\title{
Morfologi Orchidaceae di Kebun Raya Liwa Kabupaten Lampung Barat Provinsi Lampung
}

\author{
Dewi Rosanti ${ }^{1 *}$, Rizki Revici Widianjaya ${ }^{2}$ \\ *e-mail: dwrosanti@gmail.com \\ ${ }^{1}$ Program Studi Biologi FMIPA Universitas PGRI Palembang \\ ${ }^{2}$ Kebun Raya Liwa Kabupaten Lampung
}

\begin{abstract}
Research on Morphology Orchidaceae Plants in the Botanical Garden Liwa West Lampung Regency of Lampung Province, has been carried out in February March 2017, aims to examine the types and morphological descriptions Familia Orchidaceae plants in the Botanical Garden Liwa, was conducted using descriptive survey method by doing direct observation on Nursery location in Liwa Botanical Garden. Results of the study were 25 Orchid species, namely: Agrostophyllum bicuspidatum J.J.Smith., Agrostophyllum majus Hook.F., Anoectyllus sp., Appendiculata torta Blume., Arundina graminifolia Blume., Bulbophylum lepidum J.J.Smith., Bulbophyllum phalaenopsis J.J.Smith., Coelogyne asperata Lindl., Coelogyne speciosa Lindl., Dendrobium crumenatum Lindl., Dendrobium montanum J.J.Smith., Eria flavescens Blume., Eria iridifolia Hook.F., Eria nutans Lindl., Goodyera sp., Gramatophyllum speciosum Blume., Liparis gibbosa Finet., Malaxis sp., Nephelaphyllum pulcrum Blume., Paphiopedilum tonsum Rchb.F., Pholidota imbricata W.J.Hoocke., Pholidota ventricosda Blume., Pomatocalpa kunsteri Hook.F., Thecostele alata (Roxb.)Par. \& Rchb.F., dan Tricotosia feroxi Blume. Species obtained has a root system fibers with root specific functions of the roots patches and aerial roots, rod-type herbaceous and pseudobulb, type of stem growth simpodial and monopodial, single leaf, leaf types of lancet, elongated, oval, swords, ribbon and heart, flowering single and plural in bunches with growth type of flos terminalis and flos axillary.
\end{abstract}

Key words : Liwa botanical garden, morphology, Orchidaceae

\begin{abstract}
ABSTRAK
Penelitian tentang struktur morfologi Familia Orchidaceae di Kebun Raya Liwa (KRL) telah dilaksanakan pada Maret-Juli 2017, bertujuan untuk mengkaji tipe morfologi akar, batang, daun dan bunga familia Orchidaceae yang tersebar di KRL, dengan mendeskripsikan 25 species Orchidaceae yaitu Agrostophyllum bicuspidatum J.J.Smith., Agrostophyllum majus Hook.F., Anoectyllus sp., Appendiculata torta Blume., Arundina graminifolia Blume., Bulbophylum lepidum J.J.Smith., Bulbophyllum phalaenopsis J.J.Smith., Coelogyne asperata Lindl., Coelogyne speciosa Lindl., Dendrobium crumenatum Lindl., Dendrobium montanum J.J.Smith., Eria flavescens Blume., Eria iridifolia Hook.F., Eria nutans Lindl., Goodyera sp., Gramatophyllum speciosum Blume., Liparis gibbosa Finet., Malaxis sp., Nephelaphyllum pulcrum Blume., Paphiopedilum tonsum Rchb.F., Pholidota imbricata W.J.Hoocke., Pholidota ventricosda Blume., Pomatocalpa kunsteri Hook.F., Thecostele alata (Roxb.) Par. \& Rchb.F., dan Tricotosia feroxi Blume.
\end{abstract}


Spesies yang diperoleh memiliki sistem akar serabut dengan akar khusus akar udara, batang herbaceous dan pseudobulb, jenis pertumbuhan batang simpodial dan monopodial, daun tunggal, jenis daun lanset, memanjang, oval, pedang, pita dan jantung. Bunga tunggal dan majemuk dalam tandan dengan jenis pertumbuhan flos terminalis dan flos axillar.

Kata kunci: Kebun Raya Liwa, Morfologi, Orchidaceae

\section{PENDAHULUAN}

Familia Orchidaceae merupakan salah satu tanaman yang memiliki tingkat keragaman yang cukup besar dan hampir tersebar di seluruh bagian dunia. Familia Orchidaceae menempati $7-10 \%$ tumbuhan berbunga dan memiliki kurang lebih 20.000 sampai 35.000 jenis di dunia. Sekitar 4.000 sampai 5.000 jenis anggrek yang tumbuh di Indonesia. Kurang lebih 1.118 jenis anggrek yang telah diketahui spesiesnya terdapat di Sumatera (Hartini dan Puspitaningtyas, 2005).

Familia Orchidaceae telah lama dikenal oleh masyarakat luas, baik sebagai tanaman hias atau bunga hias. Familia Orchidaceae memiliki ciri khusus dengan bentuk dan warna bunga yang khas. Bunga yang khas dan unik dalam bentuk serta warna inilah yang membuat anggrek menjadi salah satu tumbuhan bunga yang populer di Indonesia.

$$
\text { Familia Orchidaceae memiliki }
$$

sistem perakaran serabut dan memiliki akar fungsi seperti akar lekat dan akar udara yang biasa tumbuh pada pseudobulb atau pada ruas - ruas batang dengan pertumbuhan sympodial dan monopodial. Pada umumnya permukaan daun familia Orchidaceae dilapisi oleh lapisan lilin yang melindungi tanaman dari serangan hama, penyakit dan pertahanan terhadap kondisi lingkungan yang kurang sesuai (Rosanti, 2013 dan Marwati, 2012).

Keanekaragaman jenis anggrek tertinggi terdapat pada ketinggian 500 -
$2.000 \mathrm{~m}$ dpl (Istikomah, 2014). Menurut Hartini dan Puspitaningtyas (2005), faktor terpenting bagi pertumbuhan anggrek ialah pergantian iklim basah dan kering yang seimbang serta curah hujan yang merata sepanjang tahun. Spesies anggrek tumbuh secara alami di tempat tempat yang tidak dipelihara oleh manusia, seperti pada hutan yang memiliki kelembapan yang tinggi (Purwantoro dkk., 2005). Berdasarkan tempat tumbuhnya anggrek dibedakan menjadi 2, yaitu anggrek epifit dan anggrek teresterial (Yahman, 2009).

Familia Orchidaceae dapat ditemukan di Kebun Raya Liwa Kabupaten Lampung Barat Provinsi Lampung. Kebun Raya Liwa dirintis pada bulan Desember 2013 sebagai tempat penelitian, pendidikan, koleksi flora khususnya tanaman hias sekaligus sebagai tempat pariwisata. Luas area kebun raya ini sebesar 86,6 Ha dan akan menjadi salah satu pusat konservasi tanaman hias yang mempresentasikan kekayaan flora TNBBS (Taman Nasional Bukit Barisan Selatan). Taman Nasional Bukit Barisan Selatan (TNBBS) merupakan salah satu hutan lindung yang menjadi habitat satwa liar baik flora maupun fauna yang terancam punah (Suyadi, 2011).

Sejauh ini belum banyak dilaporkan penelitian yang mengkaji morfologi tanaman pada Familia Orchidaceae, terutama yang terdapat di Kebun Raya Liwa Kabupaten Lampung Barat Provinsi 
Lampung, sehingga penelitian ini diharapkan dapat bermanfaat untuk pengembangan ilmu-ilmu morfologi.

\section{BAHAN DAN METODE}

Penelitian ini dilaksanakan di Kebun Raya Liwa, Kabupaten Lampung Barat, Provinsi Lampung pada bulan Februari sampai Maret 2017. Data diidentifikasi di Laboratorium Botani Science Center Universitas PGRI Palembang. Alat yang digunakan dalam penelitian ialah kamera, alat tulis, kertas label dan buku panduan Rosanti (2013). Bahan yang digunakan adalah spesimen tanaman familia Orchidaceae.

Metode yang digunakan adalah metode survey deskriptif, yaitu dengan melakukan observasi langsung pada lokasi Pembibitan di Zona L Khususnya Familia Orchidaceae di Zona L5 yang terletak bagian Utara Kebun Raya Liwa, Kabupaten Lampung Barat Provinsi Lampung. Teknik pengambilan sampel mengikuti penelitian Rosanti (2017).

Parameter pengamatan dilakukan terhadap sifat morfologi tanaman yang meliputi tipe akar, tipe batang, tipe daun, tipe bunga dengan menggunakan buku panduan dari Rosanti (2013) yang berjudul "Morfologi Tumbuhan".

\section{HASIL DAN PEMBAHASAN}

Dari hasil penelitian yang telah dilakukan di Kebun Raya Liwa, Kabupaten Lampung Barat Provinsi Lampung ditemukan 25 spesies seperti yang terdapat dalam tabel 1 di bawah ini.

Tabel 1. Spesies Orchidaceae yang terdapat di Kebun Raya Liwa, Kabupaten Lampung Barat Provinsi Lampung

\begin{tabular}{cll}
\hline No & \multicolumn{1}{c}{ Spesies } & \multicolumn{1}{c}{ Nama Lokal } \\
\hline 1. & Agrostophyllum bicuspidatum J.J.Smith. & Anggrek Agrostaphylum Bunga Cream \\
2. & Agrostophyllum majus Hook.F. & Anggrek Agrostaphylum Bunga Putih \\
3. & Anoectyllus sp. & Anggrek Tanah Bunga Merah Bata \\
4. & Appendiculata torta Blume. & Anggrek Apendik \\
5. & Arundina graminifolia Blume. & Anggrek Bambu \\
6. & Bulbophylum lepidum J.J.Smith. & Anggrek Kipas \\
7. & Bulbophyllum phalaenopsis J.J.Smith. & Anggrek Berdasi \\
8. & Coelogyne asperata Lindl. & Anggrek Mutiara \\
9. & Coelogyne speciosa Lindl. & Anggrek Selojin \\
10. & Dendrobium crumenatum Lindl. & Anggrek Merpati \\
11. & Dendrobium montanum J.J.Smith. & Anggrek Dendo \\
12. & Eria flavescens Blume. & Anggrek Mawar \\
13. & Eria iridifolia Hook.F. & Anggrek Eria Bunga Coklat \\
14. & Eria nutans Lindl. & Anggrek Eria Bunga Putih \\
15. & Goodyera sp. & Anggrek Tanah Bunga Puth \\
16. & Gramatophyllum speciosum Blume. & Anggrek Tebu \\
17. & Liparis gibbosa Finet. & Anggrek Rusa \\
18. & Malaxis sp. & Anggrek Tanah Bunga Kuning \\
19. & Nephelaphyllum pulcrum Blume. & Anggrek Tanah Daun Mati \\
20. & Paphiopedilum tonsum Rchb.F. & Anggrek Sepatu \\
21. & Pholidota imbricata W.J.Hoocke. & Anggrek Kepang \\
22. & Pholidota ventricosa Blume. & Anggrek Polidota \\
\hline
\end{tabular}


23. Pomatocalpa kunstleri Hook.F.

Anggrek Umbul - Umbul

24. Thecostele alata (Roxb.)Par. \& Rchb.F.

Anggrek The costele

25. Tricotosia feroxi Blume.

Anggrek Bulu

(Sumber : Katalog Tumbuhan Hias Kebun Raya Liwa, 2015).

Berdasarkan spesies tumbuhan

Familia Orchidaceae yang ditemukan di Kebun Raya Liwa, Kabupaten Lampung Barat Provinsi Lampung pada tabel 1 terdapat 25 spesies, yaitu : Agrostophyllum bicuspidatum J.J.Smith., Agrostophyllum majus Hook.F., Anoectyllus sp., Appendiculata torta Blume., Arundina graminifolia Blume., Bulbophylum lepidum J.J.Smith., Bulbophyllum phalaenopsis J.J.Smith., Coelogyne asperata Lindl, Coelogyne speciosa Lindl., Dendrobium crumenatum Lindl., Dendrobium montanum J.J.Smith., Eria flavescens Blume., Eria iridifolia Hook.F., Eria nutans Lindl., Goodyera sp., Gramatophyllum speciosum Blume., Liparis gibbosa Finet., Malaxis sp., Nephelaphyllum pulcrum Blume., Paphiopedilum tonsum Rchb.F., Pholidota imbricata W.J.Hoocke., Pholidota ventricosda Blume., Pomatocalpa kunsteri Hook.F., Thecostele alata (Roxb.)Par. \& Rchb.F., dan Tricotosia feroxi Blume.

Spesies orchid memiliki nama lokal, seperti anggrek bambu (Arundina graminifolia Blume.), anggrek kipas (Bulbophylum lepidum J.J.Smith.), anggrek berdasi (Bulbophyllum phalaenopsis J.J.Smith.), anggek mutiara (Coelogyne asperata Lindl.), anggrek merpati (Dendrobium crumenatum Lindl.), anggrek mawar (Eria flavescens Blume.), anggrek tebu (Gramatophyllum speciosum Blume.), anggrek rusa (Liparis gibbosa Finet.), anggrek daun mati (Nephelaphyllum pulcrum Blume.), anggrek sepatu (Paphiopedilum tonsum Rchb.F.), anggrek kepang (Pholidota imbricata W.J.Hoocke), anggrek umbul - umbul (Pomatocalpa kunstleri Hook.F.) maupun anggrek bulu (Thecostele alata (Roxb.)Par. \& Rchb.F).

Spesies Familia Orchidaceae pada tabel 1 yang ditemukan di Kebun Raya Liwa, Kabupaten Lampung Barat Provinsi Lampung sebagian besar merupakan anggrek spesies lokal yang didapatkan dari hasil eksplorasi di gunung Pesagi maupun dari kawasan Taman Nasional Bukit Barisan Selatan (TNBBS), seperti anggrek bambu (Arundina graminifolia Blume.), anggrek merpati (Dendrobium crumenatum Lindl.), dll. Spesies Gramatophyllum speciosum Blume., merupakan spesies anggrek endemik Sumatera yang dapat ditemukan di Kebun Raya Liwa Kabupaten Lampung Barat Provinsi Lampung. Sedangkan anggrek endemik Lampung sendiri belum dapat ditemukan di Kebun Raya Liwa maupun di kawasan Taman Nasional Bukit Barisan Selatan (TNBBS).

Spesies Familia Orchidaceae yang ditemukan di Kebun Raya Liwa, Kabupaten Lampung Barat Provinsi Lampung secara umum memiliki sistem perakaran serabut dengan akar khusus yakni akar udara dan akar pelekat. Anggrek yang memiliki akar khusus berupa akar udara ialah spesies Coelogyne asperata Lindl., Coelogyne speciosa Lindl., Gramatophyllum speciosum Blume., Liparis gibbosa Finet., Paphiopedilum tonsum Rchb.F., Pholidota imbricata W.J.Hoocke., dan Pomatocalpa kunstleri Hook.F. Sedangkan spesies Agrostophyllum bicuspidatum J.J.Smith, Agrostophyllum majus Hook.F., Appendiculata torta Blume., Bulbophyllum lepidum 
J.J.Smith., Bulbophyllum phalaenopsis J.J.Smith., Dendrobium crumenatum Lindl., Dendrobium montanum J.J.Smith., Eria flavescens Blume, Eria iridifolia Hook.F., Eria nutans Lindl., Pholidota ventricosa Blume., Thecostele alata (Roxb.)Par. \& Rchb.F., Tricotosia feroxi Blume., merupakan tipe anggrek yang memiliki tipe akar khusus berupa akar pelekat yang keluar dari pangkal batang semu (pseudobulb) maupun pada rimpang.

Berdasarkan tempat tumbuhnya spesies yang termasuk tipe anggrek teresterial adalah Anoectyllus sp., Arundina graminifolia Blume., Goodyera sp., Malaxis sp., Nephelaphyllum pulchrum Blume., dan Paphiopedilum tonsum Rchb.F. Spesies Appendiculata torta Blume. merupakan anggrek limtofit yang hidup pada bebatuan yang tahan terhadap sinar matahari penuh.

Secara umum semua spesies Familia Orchidaceae memiliki batang berupa batang basah, berbentuk bulat dan pendek serta dilapisi oleh pelepah daun. Batang juga ada yang termodifikasi menjadi batang semu (pseudobulb) yang tumbuh pada rimpang dan berfungsi sebagai penyimpan cadangan air, kecuali pada spesies anggrek teresterial. Arah tumbuh batang tegak sampai menggantung, dengan tipe pertumbuhan batang monopodial maupun simpodial. Menurut Rosanti (2018), tipe pertumbuhan batang dapat dibedakan menjadi 2 yaitu monopodial dan simpodial. Karena merupakan tumbuhan Class Monocotyledoneae, umumnya familia Orchidaceae memiliki tipe pertumbuhan batang monopodial.

Daun merupakan daun tunggal, memiliki struktur daun lengkap (memiliki helaian daun, tangkai daun dan pelepah daun) dan struktur daun berpelepah (daun dengan pelepah daun dan helaian daun saja). Tipe bangun daun berupa lanset, memanjang, oval, pedang, memita, dan jantung.

Bunga anggrek umumnya merupakan bunga majemuk yang tersusun dalam tandan, kecuali spesies Eria nutans Lindl., dan Paphiopedilum tonsum Rchb.F. yang berbunga tunggal. Perbungaan muncul pada ujung batang (flos terminalis) dan ketiak daun (flos axillaris). Anggrek mempunyai 3 helai sepal dan petal dengan bentuk dan warna yang beranekaragam. 1 helai petal termodifikasi menjadi bibir bunga (labellum) ang berukuran lebih besar dengan bentuk dan warna yang lebih menarik. Labellum inilah yang menjadi ciri utama untuk membedakan bunga orchid dengan bunga lainnya.

Berdasarkan hasil survey, anggrek yang paling banyak ditemukan di Kebun Raya Liwa adalah anggrek dengan genus Eria, yang memiliki tipe bunga majemuk dengan bunga yang kecil, halus dengan warna yang beraneka ragam, mulai dari putih, putih kekuningan, merah muda sampai kecoklatan. Anggrek Eria menyukai tempat yang teduh dan lembab (Hasanuddin, 2009). Genus Eria tumbuh baik di ketinggian $250-1.000 \mathrm{~m} \mathrm{dpl}$, sedangkan kawasan Kebun Raya Liwa berada di ketinggian 890 - $948 \mathrm{~m} \mathrm{dpl}$. Hal ini mendukung bahwa anggek genus Eria dapat tumbuh dengan baik di wilayah Kebun Raya Liwa.

\section{KESIMPULAN}

Berdasarkan hasil penelitian yang telah dilakukan di Kebun Raya Liwa, Kabupaten Lampung Barat Provinsi Lampung ditemukan 25 spesies Orchid dengan tipe morfologi akar berupa akar serabut dengan akar fungsi khusus berupa akar pelekat dan akar udara. Batang merupakan batang basah, berbentuk bulat kecil, berukuran pendek dilapisi pelepah daun, termodifikasi menjadi batang semu 
(pseudobulb) dengan tipe pertumbuhan simpodial dan monopodial. Daun tunggal, struktur daun lengkap dan daun berpelepah, dengan 6 tipe bangun daun (lanset, memanjang, oval, pedang, pita, dan berbangun jantung). Bunga tunggal sampai majemuk dalam tandan yang muncul di ujung batang (flos terminalis) dan ketiak daun (flos axillaris).

Dari hasil penelitian yang telah dilakukan, perlu dilakukan penelitian lebih lanjut mengenai deskripsi tipe morfologi tumbuhan Familia Orchidaceae di Kebun Raya lain.

\section{DAFTAR PUSTAKA}

Puspitaningtyas, D. M., \& Wawangningrum, H. A. R. Y. (2007).

Keanekaragaman Nepenthes di suaka alam sulasih talang-sumatera barat. Jurnal Biodiversitas, 8(2), 152-156.

Hasanuddin, H. (2010). Jenis Tumbuhan Anggrek Epifit di Kawasan Cagar Alam Jantho Kabupaten Aceh Besar. Jurnal Biologi Edukasi, 2(2), 6-14.

Istikomah, I. R. (2014). Anggrek Tanah Dan Vegetasi Lantai Di Sekitarnya Di Kawasan Jalur Pendakian Utama Gunung Andong, Magelang, Jawa Tengah. Skripsi). UIN Sunan Kalijaga Yogyakarta: Yogyakarta.

Marwati. 2012. UGM Develops Gama Orchid. News Report, 21 Februari 2012. www.ugm.ac.id/id/news.
Aziz-Purwantoro, E. A., \& Setyaningsih, F. (2005). Kekerabatan antar anggrek spesies berdasarkan sifat morfologi tanaman dan bunga. Ilmu Pertanian, 12(2005).

Rosanti, D. (2013). Morfologi Tumbuhan. Jakarta: Erlangga.

Rosanti, D. (2017). Keanekaragaman Morfologi Daun Sansevieria (Lidah Mertua) Yang Tersebar Di Kota Palembang. Sainmatika: Jurnal Ilmiah Matematika dan Ilmu Pengetahuan Alam, 14(2), 65-72.

Rosanti, D. (2018). Struktur Morfologi Batang di Taman Wisata Alam Punti Kayu Kota Palembang. Sainmatika: Jurnal Ilmiah Matematika dan Ilmu Pengetahuan Alam, 15(1), 30-34.

Suyadi, S. (2017). Deforestation in Bukit Barisan Selatan National Park, Sumatra, Indonesia. Jurnal Biologi Indonesia, 7(2), 195 - 205.

Yahman. (2009). Struktur dan Komposisi Tumbuhan Anggrek di Hutan Wisata Taman Eden Kabupaten Toba Samosir Provinsi Sumatera Utara (Tesis). Fakultas Biologi Pascasarjana, Universitas Sumatera Utara. Medan. http//repository.usu.ac.id (diakses $\begin{array}{llll}\text { tgl } & 18 & \text { Oktober 2016) }\end{array}$ 